University of Nebraska - Lincoln

DigitalCommons@University of Nebraska - Lincoln

May 2021

\title{
Lawyers Response to COVID-19 Infodemic on Social Media
}

Jibran Jamshed

The Islamia University of Bahawalpur, Pakistan, jibran_jamshed@yahoo.com

Follow this and additional works at: https://digitalcommons.unl.edu/libphilprac

Part of the Common Law Commons, Communication Technology and New Media Commons, Law and Society Commons, Legal Profession Commons, and the Social Media Commons

Jamshed, Jibran, "Lawyers Response to COVID-19 Infodemic on Social Media" (2021). Library Philosophy and Practice (e-journal). 5409.

https://digitalcommons.unl.edu/libphilprac/5409 


\section{Lawyers Response to COVID-19 Infodemic on Social Media}

\section{$\underline{\text { Abstract }}$}

Objectives: The primary objective of this study is to examine and analyze the skills and practices of lawyers in response to the misinformation/Infodemic of COVID-19 on Social Media platforms.

Research Methodology: In this quantitative study an online survey was conducted among lawyers in Pakistan. The population of the study was made up of practicing lawyers from different District Bar Associations in Pakistan. A questionnaire was distributed to collect data regarding demographic information, use of social media, response to misinformation about COVID-19 on social media and to identify the methods employed by lawyers to check the authenticity of such information. Collected data were first analyzed by using Statistical Package for Social Science (SPSS V 23) and then presented in frequency, mean, percentage, and standard deviation.

Findings: The study revealed that the majority of lawyers use social media platforms. It shows that the most popular social media platforms among the lawyers are Facebook and WhatsApp. The outcome shows that lawyers encounter fake stories about COVID-19. Critical thinking, comparison, and cross-checking are among the most commonly used techniques employed by the lawyers to check the authenticity of any information about the COVID-19 on social media. It also revealed that most of the time they share such news after checking its authenticity but sometimes they share it without confirming it.

Keywords: Social media, misinformation, Infodemic, COVID-19, Lawyers

\section{$\underline{\text { Introduction }}$}

The term 'Infodemic' is a combination of two words i.e. epidemic and information. Commonly, the term Infodemic refers to the publically available excessive amount of information which consists of both accurate and false information. Such information is generally not reliable, trustworthy, and accurate (Haouari et al., 2020). In these difficult times of the COVID-19 epidemic, the Infodemic about COVID-19 becomes a really dangerous problem and the WHO (World Health Organization) described an Infodemic as; "An overabundance of informationsome accurate and some not - that makes it hard for people to find trustworthy sources and reliable guidance when they need it"(Fact Check, 2020).

In today's modern world the major source of information is the internet and social media. An estimated 4.54 billion people in the world are active internet users, as of January 2020. The estimations are that by 2023, the total active internet users will be around 5.3 billion, which will be roughly 66 percent of the total world population. Around 3.5 billion people are using social 
media globally in 2019, which is around $45 \%$ population of the world and it is expected to be raised to $66 \%$ at the end of 2020 (Satista, 2019).

Major social media platforms include WhatsApp, WeChat, Instagram, Twitter, Weibo, and SnapChat with the majority of users are college and university students. According to one study in the United States of America USA, almost $74 \%$ of college students created their profile on Facebook, and Facebook is considered the largest used social media platform with an estimated 2.5 billion active monthly users in 2019 (Satista, 2019).

False news and rumors started to spread after the deadly outbreak of COVID-19 in the Chinese city of Wuhan in December 2019 and subsequent declaration by the World Health Organization (WHO) as Public Health Emergency of International Concern (PHEIC). Misinformation about the COVID-19 spread like wildfire on major social media platforms like Facebook, WhatsApp, and WeChat (Harrera, 2020).

The news about the Coronavirus spread like wildfire and Social Media created a unique type of hype about Coronavirus with its users posting about events in Wuhan day and night. Due to this massive amount of information coming from social media, everyone around the world remained informed about their friends and family members in China and also about the latest situation in different parts of China and the country's strategies in dealing with this epidemic (Kaur, 2020). But as this information spread fast and far away, it was distorted and ended up with more than one distorted versions all around the world (FactCheck, 2020). Romm (2020) suggests that some stories and conspiracy theories even claim that the virus was manufactured in the laboratory and its vaccine was already prepared.

It all began with the news of Chinese doctor mysterious death, who warned against the spread of coronavirus. With the news of his sudden death on social media, a barrage of misinformation spread across all major social media platforms including tightly controlled Weibo and WeChat. Users of these social media platforms shared pictures and images of the doctor, described him as a hero but also raised many questions on his sudden death (Al Jazeera, 2020; Bryan \& Agnieszka, 2018).

This situation still prevails and the misinformation about the COVID-19 is rampant on all major social media platforms like Google, Twitter, and Facebook (Harrera, 2020). Romm (2020) suggests that this situation is alarming because it creates fears among those who are looking to find true information from various sources including different type of media and social media platforms.

In this era of Infodemic, social media is one of the most popular mediums for the spread of such information. Twitter is one of the most popular social media platforms, which is a microblogging site and its usage has increased sharply in recent times (Hou et al., 2020).

\section{Literature Review}


Academics considered the Infodemic or false information about COVID-19 more dangerous and damaging to the people than any other malicious misinformation because it creates panic and forces people to make wrong and misinformed decisions about their health. The situation is so alarming that Facebook along with other major social media platforms employed people and algorithms to find and delete such false content. These companies also asked for the expertise of major health organizations to remove such false content from their platforms (Herrera, 2020).

Social Media and Infodemic both have a vital link with each other. In modern times, social platforms are known as one of the most important tools for accessing reliable and authentic news. But likewise, social media platforms are also considered as one of the most widely used platforms for the spread of fake news and propaganda. With the rapid and dangerous spread of false news/fake news on social media, its detection became ever more important for social media users. It attracted the attention of academics and media people because fake news on social media spread within minutes and it can create fear and panic of an unprecedented level as compared with other traditional forms of media (Berghel, 2017).

One of the biggest challenges for Facebook and other leading social media platforms is fake news although there are regular policy decisions and interventions to control them. An organization, who is checking facts on the false stories revealed that since 2016 there is no reduction in the fake news and propaganda on Facebook and other major social media platforms (Funke, 2018; NewsWhip, 2018).

Many experts believe that the past decade saw a revolution period in the circulation of false information, deception, and propaganda on social media platforms around the globe (Lazer et al., 2018; Flyn \& RJ, 2017). Many studies also revealed that the majority of adults who came across this fake news on social media platforms not only believe them but share them with others without checking its authenticity (Allcott \& Gentzkow, 2016; Allcott et al, 2018).

The problem of fake news and Infodemic is growing and many experts believe that situation will get worst in the future. Scholars believe that propaganda, fake stories, and misinformation will continue to affect significant events like natural disasters, elections, and political crises all over the world. They also believe that fake news already has a huge impact on many important events like these elections and natural disasters (Azzimonti, \& Fernandes, 2018; Spohr, 2017).

\section{Research Questions}

This research study is conducted to examine and analyze the skills and practices of lawyers regarding fake information about COVID 19 on Social Media. The primary objective of this study includes;

- To identify different social media platforms used by the lawyers

- To analyze the frequency of social media usage by the lawyers 
- To identify the reliable media source among the lawyers regarding COVID 19 Information

- To identify the frequency of encountering fake news about COVID 19 on Social Media Platforms

- To analyze the skills of lawyers regarding the identification of fake news regarding COVID 19 on Social Media Platforms

- To point out the information sharing behavior of lawyers regarding COVID 19

\section{Methodology}

This Quantitative study adopted the purposive online survey method. Online sampling is a relatively less expensive way of soliciting real-time data from online participants (Stimson, 2014). The data was collected between August-October 2020. The online questionnaire was developed for data collection and randomly sent to different WhatsApp groups of lawyers for pilot testing. After the questionnaire was returned, they were aligned and adjusted according to the suggestion given by the respondents. The questionnaire was then sent again on different WhatsApp groups of lawyers in Pakistan.

First, a formal request was made to the administrator and the members of groups on the intent of the survey, and after the consent was given by the administrator, the link to the survey was shared on the WhatsApp group platform. The survey took around 5 minutes to complete and it consists of two parts. In total, the message was sent to 732 respondents, and 303 responded and completed the survey in time.

The purpose of this study is to investigate the misinformation about COVID-19 on social media among lawyers. Statistical Package for Social Science (SPSS) version 23 is used to analyze and compute the data received from respondents.

\section{Findings}

In this study the majorities (85.5\%) of respondents were male and most of them (45.2\%) belong to the age group of 31 to 40 years (Table 1).

Table 1: Demographic \& Age Information of the Respondents

\begin{tabular}{|l|c|c|}
\hline \multicolumn{1}{|c|}{ Gender } & Frequency & Percent \\
\hline Male & 259 & 85.5 \\
\hline Female & 44 & 14.5 \\
\hline \multicolumn{2}{|c|}{ Age Group } & \\
\hline
\end{tabular}




\begin{tabular}{|l|c|c|}
\hline $21-30$ Year & 137 & 45.2 \\
\hline $31-40$ Year & 114 & 37.6 \\
\hline $41-50$ Year & 34 & 11.2 \\
\hline 50 and above & 18 & 5.9 \\
\hline
\end{tabular}

The respondents were asked the question about the frequency of using social media. It was found that the majority of them $(77.9 \%)$ use social media more than twice a day. A very thin minority of respondents $(4 \%)$ use social media daily and only $(0.7 \%)$ use social media occasionally (Table 2).

Table 2: Frequency of using Social Media

\begin{tabular}{|l|c|c|}
\hline \multicolumn{1}{|c|}{ Use of Social Media } & Frequency & Percent \\
\hline More than twice day & 236 & 77.9 \\
\hline Twice a day & 53 & 17.5 \\
\hline Daily & 12 & 4.0 \\
\hline Occasionally & 2 & .7 \\
\hline
\end{tabular}

Diagram 1: Bar chart about frequency of using social media 


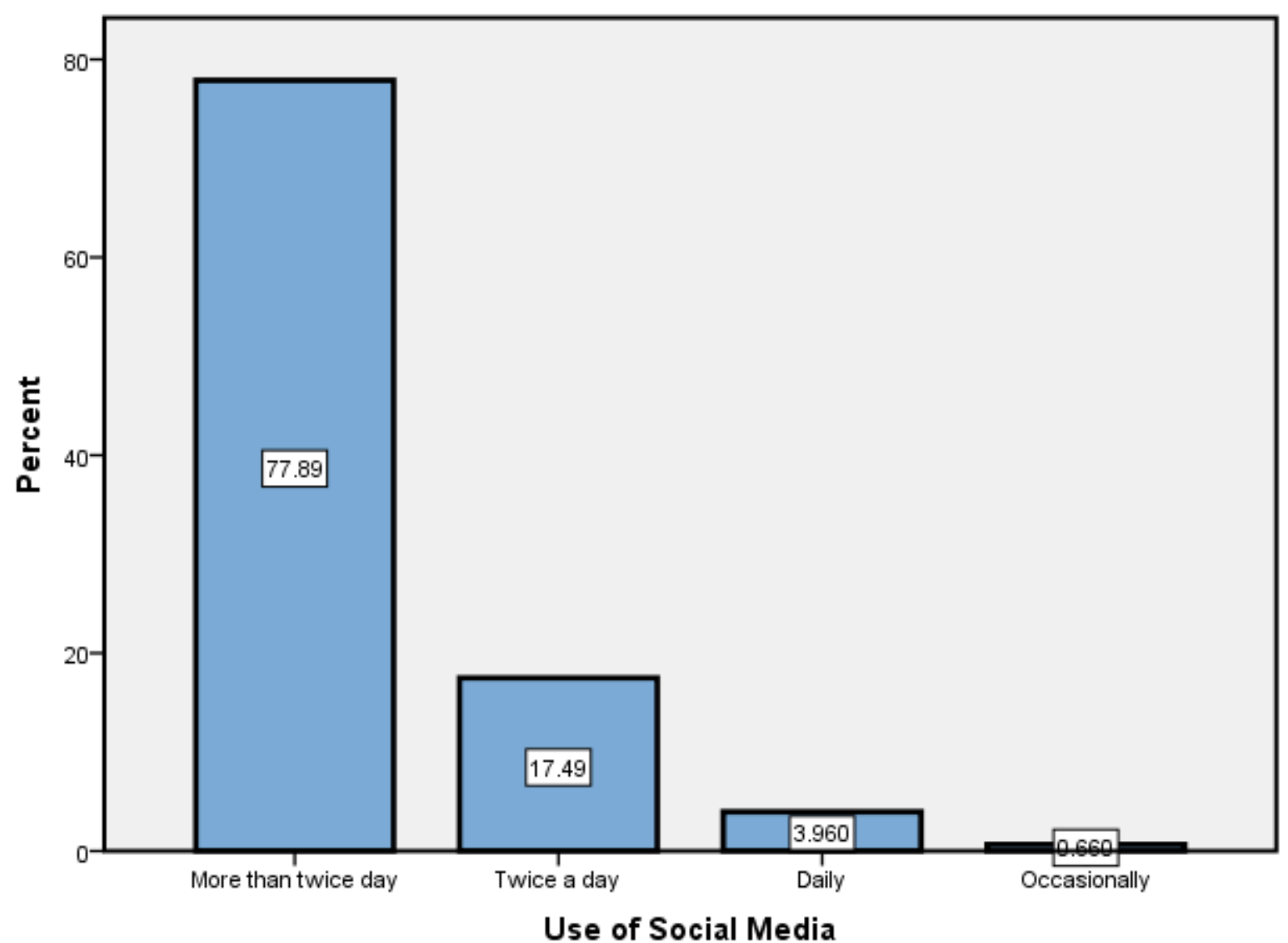

Respondents were asked 7 statements regarding their frequency of using different social media platforms. Two statements received a mean value of around 4, one of them is 'How often I use Facebook' $(\mathrm{M}=4.13, \mathrm{SD}=.846)$ and the other is 'How often I use WhatsApp' $(\mathrm{M}=4.09$, $\mathrm{SD}=.954$ ), which mean the majority of respondents always use Facebook and WhatsApp. However, four statements received the mean value around 2, which means respondents rarely use Instagram, LinkedIn, Pinterest, and other social media platforms (Table 3).

Table 3: Frequency of using different social media platforms

\begin{tabular}{|l|c|c|c|}
\hline \multicolumn{1}{|c|}{ Statement } & Valid & Mean & $\begin{array}{c}\text { Std. } \\
\text { Deviation }\end{array}$ \\
\hline How often I use Facebook & 303 & 4.13 & .846 \\
\hline How often I Use WhatsApp & 303 & 4.09 & .954 \\
\hline How often I Use Twitter & 303 & 2.50 & 1.103 \\
\hline How often I Use Instagram & 303 & 2.01 & 1.028 \\
\hline How often I Use LinkedIn & 303 & 1.72 & .982 \\
\hline How often I Use Pinterest & 303 & 1.63 & .807 \\
\hline
\end{tabular}




\begin{tabular}{|l|l|l|l|}
\hline How often I Use Other Social Media Platforms & 303 & 1.51 & .805 \\
\hline
\end{tabular}

Scale: 1=Never, 2=Rarely, 3=Sometimes, 4=Often, 5=Always

Respondents were asked five statements about the reliability of different kind of Media regarding information about the COVID 19. Out of these 5 statements, two statements received a mean value of 4 i.e. ' $\mathrm{TV}$ is the most reliable source of information on COVID 19' $(\mathrm{M}=4.21, \mathrm{SD}=.822)$ and 'Newspaper is the most reliable source of information on COVID 19' $(\mathrm{M}=4.00, \mathrm{SD}=.791)$, which revealed that respondents often rely upon TV and Newspaper as a reliable source of information about the COVID 19. On the other hand, two statements received the mean value of around 2 which implies that friends and family along with websites are the least reliable sources of information about COVID 19 (Table 4).

Table 4: Reliability of different kind of Media regarding information about COVID 19

\begin{tabular}{|l|c|c|c|}
\hline \multicolumn{1}{|c|}{ Statement } & Valid & Mean & $\begin{array}{c}\text { Std. } \\
\text { Deviation }\end{array}$ \\
\hline $\begin{array}{l}\text { TV is the most reliable source of Information on COVID } \\
19\end{array}$ & 303 & 4.21 & .822 \\
\hline $\begin{array}{l}\text { Newspaper is the most reliable source of Information on } \\
\text { COVID 19 }\end{array}$ & 303 & 4.00 & .791 \\
\hline $\begin{array}{l}\text { Social Media is the most reliable source of Information } \\
\text { on COVID 19 }\end{array}$ & 303 & 2.54 & 1.121 \\
\hline $\begin{array}{l}\text { Friends and Family are the most reliable source of } \\
\text { Information on COVID 19 }\end{array}$ & 303 & 2.39 & .938 \\
\hline $\begin{array}{l}\text { Websites are the most reliable source of Information on } \\
\text { COVID 19 }\end{array}$ & 303 & 2.17 & .995 \\
\hline
\end{tabular}

Scale: 1=Never, 2=Rarely, 3=Sometimes, 4=Often, 5=Always

The respondents were asked six statements about the frequency of encountering fake news on social media platforms about COVID 19. Two statements received a mean value around 4, "I often encounter fake news about COVID 19 on Facebook" $(\mathrm{M}=4.20, \mathrm{SD}=.870)$, "I often encounter fake news about COVID 19 on WhatsApp" $(\mathrm{M}=4.02, \mathrm{SD}=.840)$, which shows that respondents often encounter fake news about COVID 19 on Facebook and WhatsApp. However, four out of six statements received a mean value around 3 which shows that respondents sometimes encounter fake news about COVID 19 on Twitter, Instagram, Pinterest, and LinkedIn (Table 5). 
Table 5: Frequency of encountering fake news on social media platforms about COVID 19

\begin{tabular}{|l|c|c|c|}
\hline \multicolumn{1}{|c|}{ Statement } & Valid & Mean & $\begin{array}{c}\text { Std. } \\
\text { Deviation }\end{array}$ \\
\hline $\begin{array}{l}\text { I often encounter fake news about COVID 19 on } \\
\text { Facebook }\end{array}$ & 303 & 4.20 & .870 \\
\hline $\begin{array}{l}\text { I often encounter fake news about COVID 19 on } \\
\text { WhatsApp }\end{array}$ & 303 & 4.02 & .840 \\
\hline $\begin{array}{l}\text { I often encounter fake news about COVID 19 on the } \\
\text { Twitter }\end{array}$ & 303 & 3.24 & 1.234 \\
\hline $\begin{array}{l}\text { I often encounter fake news about COVID 19 on } \\
\text { Instagram }\end{array}$ & 303 & 3.00 & 1.044 \\
\hline $\begin{array}{l}\text { I often encounter fake news about COVID 19 on } \\
\text { Pinterest }\end{array}$ & 303 & 2.74 & .855 \\
\hline $\begin{array}{l}\text { I often encounter fake news about COVID 19 on } \\
\text { LinkedIn }\end{array}$ & 303 & 2.61 & .750 \\
\hline Scat I=Ner, 2=Ran
\end{tabular}

Scale: $1=$ Never, $2=$ Rarely, $3=$ Sometimes, $4=$ Often, 5=Always

Respondents were asked the question about how they check the authenticity of COVID 19 information found on different social media platforms. Six statements were given to them in the questionnaire to get the answer to the above-mentioned question. Two of them received a mean value around 4 i.e. "I use my Critical thinking and common sense" $(\mathrm{M}=4.31, \mathrm{SD}=.958)$, "I compare the news of social media with reliable print or electronic media resources" $(M=3.60$, $\mathrm{SD}=.707$ ), which means that respondents often check the authenticity of information about COVID 19 by their common sense and by comparing the information with reliable print and electronic media. However, the statement "I use sources and authentic online fact-checking tools" $(\mathrm{M}=1.89, \mathrm{SD}=1.224)$ received a mean value around 2, which implies that respondents rarely use online fact-checking tools for information authentication (Table 6).

Table 6: How to check the authenticity of COVID 19 information on Social Media

\begin{tabular}{|l|r|r|r|}
\hline \multicolumn{1}{|c|}{ Statement } & \multicolumn{1}{|c|}{ Valid } & \multicolumn{1}{|c|}{ Mean } & \multicolumn{1}{|c|}{$\begin{array}{c}\text { Std. } \\
\text { Deviation }\end{array}$} \\
\hline How I check the authenticity of information regarding COVID 19 on Social Media \\
\hline I use my own Critical thinking and common sense & 303 & 4.31 & .958 \\
\hline $\begin{array}{l}\text { I compare the news of social media with reliable print or } \\
\text { electronic media resources }\end{array}$ & 303 & 3.60 & .707 \\
\hline $\begin{array}{l}\text { I compare the news on social media with official } \\
\text { websites or reputable organization }\end{array}$ & 303 & 2.89 & .881 \\
\hline I read the whole story and then make a judgment about it & 303 & 2.29 & .899 \\
\hline I contact with my friends and family to check it & 303 & 2.15 & .846 \\
\hline I use sources and authentic Online fact-checking tools & 303 & 1.89 & 1.224 \\
\hline
\end{tabular}


Scale: $1=$ Never, $2=$ Rarely, $3=$ Sometimes, $4=$ Often, $5=$ Always

Respondents were asked four statements about their news sharing behavior regarding COVID 19 information. One statement received a mean value of 4 i.e. "I share news about COVID 19 on social media if it came from a reliable source $(\mathrm{M}=3.76, \mathrm{SD}=.703)$, which means respondents often share such news if it came from reliable sources. Three statements received the mean value around 3, which means respondents sometimes share news about COVID 19 on social media after completely checking its authenticity $(\mathrm{M}=3.41, \mathrm{SD}=.965)$, share it if it is shared by a person whom respondent trusts $(\mathrm{M}=2.94, \mathrm{SD}=1.001)$ and share it without checking its authenticity $(\mathrm{M}=2.94, \mathrm{SD}=1.008)$, (Table 7).

Table 7: News sharing behavior about the information regarding COVID 19

\begin{tabular}{|l|r|r|r|}
\hline \multicolumn{1}{|c|}{ Statement } & Valid & Mean & $\begin{array}{c}\text { Std. } \\
\text { Deviation }\end{array}$ \\
\hline \multicolumn{3}{|l|}{} \\
\hline $\begin{array}{l}\text { I share news about COVID 19 on social media if it came } \\
\text { from a reliable source }\end{array}$ & 303 & 3.76 & .703 \\
\hline $\begin{array}{l}\text { I share news about COVID 19 on social media after } \\
\text { completely checking its authenticity }\end{array}$ & 303 & 3.41 & .965 \\
\hline $\begin{array}{l}\text { I share news about COVID 19 on social media if it is } \\
\text { shared by a person whom I trust }\end{array}$ & 303 & 3.14 & 1.001 \\
\hline $\begin{array}{l}\text { I share news about COVID 19 on social media without } \\
\text { checking its authenticity }\end{array}$ & 303 & 2.94 & 1.008 \\
\hline
\end{tabular}

Scale: $1=$ Never, $2=$ Rarely, $3=$ Sometimes, 4=Often, 5=Always

\section{Discussions}

The results of this study show that the majority of respondents use social media platforms and 77.9 percent of them use social media more than twice a day. It also means that social media usage is very high among lawyers.

The outcome of this study shows that Facebook is the most commonly used social media platform among the lawyers along with WhatsApp which secondly to Facebook. Results showed that LinkedIn, Pinterest, and other social media platforms are least popular among the lawyers and they rarely use these social media platforms.

The study found out that majority of lawyer considers TV and Newspapers as the most reliable form of media for the information about COVID-19. It is interesting to note that Social Media, Friends, and Websites are not considered a reliable source of information among the legal fraternity in Pakistan. The majority of lawyers rarely use websites as an authentic source of information.

The study also highlighted that Facebook and WhatsApp are the social media platforms where most of the time lawyers encounter fake information about the COVID 19. Although they 
encounter fake news about COVID-19 on other social media platforms but its frequency is much lower than Facebook and WhatsApp. Daniel \& Demuyakor (2020) backed the finding of this study as they reported that major sources of fake news about COVID-19 was mainly the social media. They also suggested that the best way to avoid the fake news is to reduce the usage of social media. Although, it might seems a harsh solution to this problem but this view point is endorsed by other scholars like (Choy \& Chong, 2019) who suggested that one should avoid the story whose source is not accurate and reliable.

The study highlights the commonly used methods employed by lawyers to check the authenticity of any information about COVID-19 on social media. The study explored that the majority of lawyers rely on their critical thinking and common sense while checking the authenticity of any COVID-19 related information on social media. Daniel \& Demuyakor (2020) also backed the finding of this study by reporting that one of the best ways of recognizing fake news is to apply critical thinking and due diligence. Logical analysis and proper value judgments are the best ways to detect fake news on social media. Similar findings reported in other studies that critical thinking skills are key to detecting the fake news on social media (Berghel 2017; Rubin et al., 2016).

This study also found out that comparing and cross-checking any information with other sources of media is also one of the major tools used by the lawyers to check the authenticity of any news on social media about the COVID-19. Recasens (2013) pointed out in this study that it is significant to double-check the news before making any decisions on its basis. This finding was also backed by Daniel \& Demuyakor (2020) who reported that analyzing, checking, and comparing any news with other sources is of paramount importance. Before making any decisions based on such news, it is important to double-check its authenticity by comparing it with other sources.

Interestingly the study finds out that lawyers rarely use any sources and authentic online factchecking tools to check the authenticity of any information. It also shows the mindset and trend among lawyers who do not rely on online tools and digital resources.

The study also found out that the majority of lawyers share the COVID-19 related information on social media if it came from some reliable source. But it is also revealed that sometimes lawyers do share news about COVID-19 without checking its authenticity or cross-checking it. Cross-checking fake news about COVID-19 is important as it is also supported by (UNESCO 2018, P.70), who described that it is very important for people to cross-check any news before sharing it with other people.

To combat the menace of fake news about COVID-19 on social media is to enact such laws that curb the spread of misinformation on social media. Zubair \& Qadir (2019) also suggested that laws are of paramount importance in combating the misinformation on social media platforms. 
Another way to curb the menace of fake news about COVID-19 on social media is to spread credible information to the users, this view is also endorsed by (Schmitt et al, 2018).

All institutes and universities need to play their role in creating awareness among the people regarding misinformation about the COVID-19. This idea of inclusive participation of all in combat against the COVID-19 misinformation is endorsed by many scholars like (Bode \& Vraga, 2017; Jolley \& Douglas, 2012; Lewandowsky \& Cook, 2020; Douglas et al., 2019).

\section{$\underline{\text { Limitations }}$}

Only one social media community was used to collect the data from respondents which is the first limitation of this study. Another limitation is that respondents belong to a particular country hence it cannot be said that it represents the lawyer community all over the world.

\section{$\underline{\text { Conclusion }}$}

Misinformation and fake news about the COVID-19 led to panic and fear in society. This study contributes to the literature on the misinformation/Infodemic about the COVID-19. It also provides information about the perception of lawyers about the COVID-19 Infodemic on Social Media. The findings of this study concluded that the majority of lawyers use social media platforms. It also concluded that the majority of lawyers encounter fake news about COVID-19 on social media and particularly on Facebook and WhatsApp. It shows that most of the lawyers use their critical thinking to check the authenticity of any such information about COVID-19 on social media. 


\section{$\underline{\text { References }}$}

Al Jazeera. (2020, February 10). The doctor who warned about Coronavirus dies | China | Al Jazeera. https://www.aljazeera.com/programmes/newsfeed/2020/02/doctor-warned-coronavirusdies200210110130361.html

Berghel, H. (2017). Lies, Damn Lies, and Fake News. The Computer Society.

Bode, L., \& Vraga, E. K. (2017). See Something, Say Something: Correction of Global Health Misinformation on Social Media. Health Communication, 1-11.

http://dx.doi.org/10.1080/10410236.2017.1331312

Christiansen, B., \& Piekarz, A. (Eds.). (2018). Global Cyber Security Labor Shortage and International Business Risk. IGI Global.

Choy, M., \& Chong, M. (2019). Seeing Through Misinformation : A Framework for Identifying Fake Online News Director of Operations and Technology, SSON Analytics. Associate Professor, Corporate Communication (Practice), Singapore Management. 1-14. https://arxiv.org/ftp/arxiv/papers/1804/1804.03508.pdf

Daniel Ong'ong'a, O., \& Demuyakor, J. (2020). Coronavirus (COVID-19)" infodemic" in the Social Media: A Survey of Kenya International Students in China.

Douglas, K. M., Uscinski, J. E., Sutton, R. M., Cichocka, A., Nefes, T., Ang, C. S., \& Deravi, F. (2019). Understanding Conspiracy Theories. Advances in Political Psychology, 40(. 1), 1-33.

FactCheck.org. (2020, February 7). Explaining Coronavirus Misinformation. FactCheck.Org. https://www.factcheck.org/2020/02/explaining-coronavirus-misinformation/

Funke, D. (2018). Fact-checkers have debunked this fake news site 80 times. It's still publishing on Facebook. Poynter. Org

Haouari, F., Hasanain, M., Suwaileh, R., \& Elsayed, T. (2020). \$ltexttt \{ArCOV-19\} \$: The First Arabic COVID-19 Twitter Dataset with Propagation Networks. arXiv preprint arXiv:2004.05861.

Herrera, S. (2020). Coronavirus misinformation lives online, despite efforts to stamp it out. Wall St $J$.

Hou, Z., Du, F., Jiang, H., Zhou, X., \& Lin, L. (2020). Assessment of public attention, risk perception, emotional and behavioural responses to the COVID-19 outbreak: social media surveillance in China. Risk Perception, Emotional and Behavioural Responses to the COVID-19 Outbreak: Social Media Surveillance in China (3/6/2020). 
Jolley, D., \& Douglas, K. M. (2012). The social consequences of conspiracism: Exposure to conspiracy theories decreases intentions to engage in politics and to reduce one's carbon footprint. British Journal of Psychology, 1-22. https://doi.org/10.1111/bjop.12018

Kaur, H. (2020, March 5). Coronavirus myths and misinformation, debunked. CNN. https://www.cnn.com/2020/03/04/health/debunking-coronavirus-myths-trnd/index.html

Lewandowsky, S., \& Cook, J. (2020). The Conspiracy Theory Handbook. http://sks.to/conspiracy.

NewsWhip. (2018). Navigating the Facebook algorithm change: 2018 report.

https://growthhackers.com/articles/navigating-the-facebook-algorithm-change-2018-report-bynewswhip

Recasens, M., Cristian-Mizil, D.-N., \& Jurafsky, D. (2013). Linguistic Models for Analyzing and Detecting Biased Language. Association for Computational Linguistics.

Romm, T. (2020). Fake cures and other coronavirus conspiracy theories are flooding WhatsApp, leaving governments and users with a "sense of panic.". Washington Post.

Rubin, V. L., Conroy, N. J., Chen, Y., \& Cornwell, S. (2016). Fake News or Truth? Using Satirical Cues to Detect Potentially Misleading News. 7-17.

Schmitt, J. B., Rieger, D., \& Ernst, J. (2018). Critical Media Literacy and Islamist Online Propaganda: The Feasibility, Applicability, and Impact of Three Learning Arrangements. 12, 119. https://doi.org/10.4119/UNIBI/ijcv.642

UNESCO. (2018). Journalism, ' Fake News' \& Handbook for Journalism Education and Training. the United Nations Educational, Scientific and Cultural Organization, 7, place de Fontenoy, 75352 Paris 07 SP, France. http://www.unesco.org/open-access/terms-use-ccbysa-en

World Social Media Statistics https://www.Statista.com/

Zubair, T., \& Qadir, J. (2019). On Combating Fake News, Misinformation, and Machine Learning Generated Fakes : Insights from the Islamic Ethical Tradition. October. https://www.researchgate.net/publication/336604412 